\title{
Report of the First Training the Colonoscopy Trainers Courses Held in India
}

\author{
Pandurangan Basumani ${ }^{1} \quad$ Mark Thomas Donnelly² Stuart Anthony Riley ${ }^{2} \quad$ Md. Thoufeeq $^{2}$ Ramakrishnan Ravi \\ 1Department of Gastroenterology, Dr Rela Institute and Medical \\ Centre, Chennai, India \\ ${ }^{2}$ Department of Gastroenterology, Sheffield Teaching Hospitals, \\ Sheffield, United Kingdom

\begin{abstract}
Address for correspondence Pandurangan Basumani, MD, FRCP (UK),, Department of Gastroenterology, Dr Rela Institute and Medical Centre, CLC Works Road, Chennai 600044, India (e-mail: pbasumani@gmail.com).
\end{abstract}

J Digest Endosc:2020;11:205-208

\begin{abstract}
Background and Aim Training the colonoscopy trainers (TCT) courses have become widespread in the United Kingdom and elsewhere but have never taken place in India. This is an account of the first such course delivered in India with an attempt to demonstrate its impact on the training knowledge and abilities of the delegates.

Materials and Methods Twelve independent colonoscopists, all with a training remit, underwent a structured 2-day TCT course. They were asked retrospectively to self-assess their knowledge and training skills across a number of metrics using a 1-10 scale, before and after attending the course.

Statistical Analysis Scores were analyzed by the Wilcoxon's two-tail test

Results Delegates training knowledge and skills improved significantly across all

Keywords seven metrics ( $p<0.01$ for all).

- colonoscopy

- education

- pilot project

Conclusion The TCT is highly suitable in the Indian endoscopic environment and very effective in improving the training knowledge and skills of even experienced colonoscopists.
\end{abstract}

\section{Introduction}

Several studies have shown that screening programscolonoscopy being the key investigation-improve survival in patients with colorectal cancer by picking up the disease at an earlier stage. ${ }^{1-3}$ Colonoscopy in India is well established as an essential tool in the investigation and management of colorectal disease. However, there are no formalized dedicated colonoscopy training courses in India, and training is largely through apprenticeships with trainers during gastroenterology fellowship. The trainers themselves often have little formal training in practical skills training.

The United Kingdom (UK) was in an analogous position 25 years ago.

Around the same time, the first large audit of colonoscopy practice in the UK was published. ${ }^{4}$ This revealed for the first time concerning data about colonoscopy practice in the UK. Completion rates were low (adjusted cecal intubation rate $=56.9 \%$ ), complications were much higher than was thought (perforation rate 1:7694). Moreover, supervision and training were of a highly variable and generally low standard (17\% supervised for first 100 colonoscopies and 39.3\% had attended a training course ${ }^{4}$ ).

Concerned that the endoscopy service was unfit to support the effective introduction of a national Bowel Cancer Screening Program in an asymptomatic population, a large investment was made to improve colonoscopy training across the nation. This, in part, consisted of the setting up of 10 endoscopy training centers (now expanded to more than $20^{5}$ ) to develop and deliver various hands-on training courses.

The other major development to improve endoscopy standards was the formation of the JAG (Joint Advisory Group on gastrointestinal endoscopy), which although initially focused on improving endoscopy training, now has a broad remit across all aspects of endoscopy, including the accreditation of individual endoscopists and endoscopy units. ${ }^{6}$

When the UK audit was repeated a decade after the introduction of the training program and associated courses together with the establishment of JAG, it became clear that 
there had been as marked improvement in the quality of colonoscopy. ${ }^{7}$

It subsequently became obvious that the most important and impactful of these courses was the training the colonoscopy trainer course. This course has evolved and developed over the last 15 years, and seeks to improve and standardize the teaching of colonoscopic skills by training colonoscopy trainers to train better. ${ }^{8}$ It is thought to be the most efficient and effective way of improving the practice of colonoscopy across a whole endoscopy service. ${ }^{8}$

In addition, a relatively recent training tool has been the introduction of three-dimensional magnetic imaging systems (we used Olympus ScopeGuide during the courses). These allow the colonoscopist to view the configuration of loops inside the patient, allowing for more effective and proactive loop management. ${ }^{9}$ They are an invaluable tool for teaching loop recognition and resolution to novice colonoscopists. Such systems are widespread-although not universal-in the UK. The use of this technology is very limited in India.

Training in endoscopy is offered in structured postgraduate gastroenterology program (DM and DNB). Though variable in quantity and quality, overall the exiting candidates are competent to provide service as independent practitioners in their chosen workplace. However, it is also noted that no comparable data like UK audit are available about safety, completion rates, and effectiveness of colonoscopy in India.

Our aim therefore was to deliver two TCT courses employing a modified UK format and utilizing the ScopeGuide as a training aid. This is an account of the first such courses.

\section{Materials and Methods}

\section{Objectives of the Training the Colonoscopy Trainers Course}

Objectives of this course were as follows: the delegates at the end of the course will

- Understand and apply a framework for effective skills teaching

- Explain the need for conscious competence in both performing and in teaching colonoscopy

- Understand the benefit of identifying specific personal learning objectives

- List the common terms and language used in endoscopy training

- Understand the concept of cognitive overload (dual task interference) and the need for an adaptive approach to communication techniques in skills training

- Provide performance enhancing feedback and performance enhancing instruction

\section{Practicalities of the Course}

Consultant gastroenterologists (PB and RR) from the department of gastroenterology in a large multispecialty hospital, Dr. Rela Institute and Medical Centre (DRIMC Chennai) invited three U.K. consultant gastroenterologists (MTD, SAR, and MT) from Sheffield Teaching Hospitals (STH) UK to conduct two 2-day TCT courses at the DRIMC. The three UK-based gastroenterologists are experienced endoscopy course trainers and between them, have delivered around 200 hands-on endoscopy training courses, STH being one of the original 10 endoscopy training centers.

Major endoscopy training units from much of South India (Chennai, Bengaluru, Hyderabad, Kochi, Manipal, Puducherry, and others) were asked to nominate delegates to take part in these pilot courses.

All delegates were independent consultant endoscopists with an existing or future commitment to training gastroenterology fellows in endoscopy.

The courses followed a standard UK format. The day 1 consists of the introduction of some concepts of adult educational theory. These included structured training, the importance of segmentation when teaching complex practical skills, recognition of conscious competence as an invaluable tool in teaching, SMART (specific, measurable, achievable, relevant, and timely) objective setting, the role of open and closed discussions in developing mini-tutorials, performance enhancing instruction, and the importance of feedback to the trainee and of reflection to the trainer. No PowerPoint slides were used during the course; training methods were largely interactive and included role play with extensive one-to-one training.

The day 2 consists of the delegates training each other on live patient cases while not in role play. The delegates got the chance to employ their newly acquired skills, training each other using these new techniques. A member of the training faculty was present during each procedure, prompting the delegate and offering constructive feedback on the training skills displayed at the end of each procedure. All patients were given Propofol sedation by an experienced anesthetic team.

At the end of the second day, delegates were encouraged to offer feedback to the faculty on the course, its content, and delivery.

Throughout the courses were conducted in an enthusiastic, nonthreatening, and friendly atmosphere. The aim of the courses is not to improve colonoscopy technique but undoubtedly, spending 2 days talking and learning about colonoscopy training means that both delegates' and indeed the faculty's own colonoscopic skills can be enhanced.

\section{Measuring the Impact of the Courses}

After each course, all six delegates-12 in total-were asked to retrospectively assess the impact of the course on their knowledge of training, training styles, and techniques across a number of metrics.

They were many as follows:

- Using structured interventions

- Segmenting training

- Setting SMART objectives

- Understanding conscious competence

- Avoiding dual task interference

- Giving performance enhancing feedback

- Self-reflection on being a trainer 
Details of objective learning outcomes and adult learning principles are beyond the scope of this article. In brief, the central function of the TCT is to provide the delegate with a pragmatic structure for training colonoscopy based on sound educational principles. Such an approach is associated positive trainer and trainee feedback and improved trainee outcomes.

The importance of learning outcomes was introduced to delegates using examples of other complex visual and motor skills; for example, a delegate was asked how he drove to workplace that morning. This exercise brought out many key principles in adult learning including translating unconscious competence into conscious competence and need for segmentation (chunking) when teaching new information. Role play was employed to demonstrate and hone feedback skills in different training situations, for example, performance enhancing feedback with familiar trainees, Pendleton's rule-based feedback with new trainee, or after a particularly difficult training session.

The delegates were asked to use a 1-10 scale to score themselves before and after the course. All delegates sent their responses to secretarial staff who collated the data, so feedback was anonymous to authors.

Since the courses, both delegates and faculty have set up a shared social media platform where there is self-reflection, mutual encouragement, and continuing feedback.

\section{Use of ScopeGuide}

The application and use of the ScopeGuide was explained to the delegates on day 1 . On day 2 each delegate used the ScopeGuide, with faculty's guidance, to monitor progress and to proactively prevent and manage loop formation. Delegates were able to incorporate ScopeGuide imaging following limited practice. Although not an essential tool, all found it a useful training adjunct. In particular, it allowed trainers to visually demonstrate the real time dynamics of loop formation and resolution without the need to take the colonoscope from the trainee.

\section{Results: Background Data}

The courses were attended by 12 delegates in total.

They were all practicing as independent colonoscopists with a range of independent practice from 1 to 10 years ( median $=3$ years).

The range of experience of independent practice was from 110 to more than 5,000 colonoscopies (median = 800 colonoscopies).

None of the delegates had received training on how to teach colonoscopy previously.

\section{Results}

Impact of Courses on Training Knowledge and Skills The following table summarizes the impact of the courses on delegates training ability and understanding of training techniques.

\begin{tabular}{|l|l|l|l|}
\hline $\begin{array}{l}\text { Learning } \\
\text { outcome }\end{array}$ & $\begin{array}{l}\text { Ability/ } \\
\text { understanding } \\
\text { before Median } \\
\text { (range) }\end{array}$ & $\begin{array}{l}\text { Ability/ } \\
\text { understanding } \\
\text { afterward } \\
\text { Median (range) }\end{array}$ & $\begin{array}{l}\text {-Value } \\
\text { (Wilcoxon) } \\
\text { comparing } \\
\text { before and } \\
\text { after }\end{array}$ \\
\hline $\begin{array}{l}\text { Apply } \\
\text { structure }\end{array}$ & $3(1-5)$ & $8(6-9)$ & $<0.01$ \\
\hline $\begin{array}{l}\text { Segment } \\
\text { training }\end{array}$ & $3(1-6)$ & $8(7-9)$ & $<0.01$ \\
\hline $\begin{array}{l}\text { Set SMART } \\
\text { objectives }\end{array}$ & $1(1-4)$ & $8(7-9)$ & $<0.01$ \\
\hline $\begin{array}{l}\text { Understand } \\
\text { conscious } \\
\text { competence }\end{array}$ & $2(1-5)$ & $8(7-9)$ & $<0.01$ \\
\hline $\begin{array}{l}\text { Avoid } \\
\text { dual task } \\
\text { interference }\end{array}$ & $2(1-7)$ & $9(7-10)$ & $<0.01$ \\
\hline $\begin{array}{l}\text { Use } \\
\text { performance } \\
\text { enhancing } \\
\text { feedback }\end{array}$ & $3(1-5)$ & $8(8-9)$ & $<0.01$ \\
\hline $\begin{array}{l}\text { Reflect on } \\
\text { training }\end{array}$ & $3(1-4)$ & $8(7-9)$ & $<0.01$ \\
\hline
\end{tabular}

Abbreviation: SMART, specific, measurable, achievable, relevant, and timely.

Additionally, delegates were asked to assess what percentage of the course comprised effective learning; they were asked to rate the course overall and the postcourse materials (using a 1-10 scale). These results are shown in the following table as [median (range)].

\begin{tabular}{|l|l|}
\hline Effective learning & $90 \%(60-100) \%$ \\
\hline Course rating overall & $10(8-10)$ \\
\hline Keynote hand-outs & $10(8-10)$ \\
\hline
\end{tabular}

\section{Results: Other Feedback}

Delegates were asked to give feedback to the faculty about the course, its content, and delivery immediately after the courses and subsequently via a social media platform.

A selection of this feedback appears below:

Which things did you most like about the course?

- "One-to-one interaction with personal attention to each delegate"

- "Good focus on practical ways to improve training"

- "Gave me an entirely different outlook toward teaching in general as well as with regard to colonoscopy"

- "It was among the best academic courses that I have attended in the last 10 years. I have recommended it to all my endoscopy friends! "

How could the course be improved?

- "Nothing really"

- "More hands-on training would be nice"

- "Videos of sigmoid loop avoidance or demonstrations of same could be included"

- "Demonstration of colonoscopy and ScopeGuide by faculty" 


\section{Discussion}

This is a report of what we believe are the first TCT courses conducted in India. The courses delivered were slightly adapted UK TCT courses. TCT courses in the UK are seen as a central part of a strategy to improve endoscopy training and subsequently, endoscopy quality. They have been introduced and developed in the UK over the previous 15 years and are very different now, both in content and delivery than when they first started.

The authors were interested to discover if this course could be delivered in the Indian setting and whether it would be effective and have a positive measurable impact on the training skills of Indian consultant endoscopists. The result is a resounding "yes."

Objective learning outcomes were quite new to all delegates, albeit their variable work experience but high-achieving academic careers. This is reflected in the initial scores. It is gratifying that this gap in teaching skill can be bridged effectively by a brief but focused intervention.

There had been concern expressed before the courses about whether differences between the UK and India culturally and clinically would adversely affect the delivery and effectiveness of the course. For example, the delegates were initially surprised that there were few if any PowerPoint slides used in the course and that much was expected of them as delegates, for example in role play scenarios. In fact, they universally found the methods and style of training to be refreshing, innovative, and moreover, very effective.

A large part of the course consists of training trainers to give effective and performance-enhancing feedback. Sometimes, giving feedback, especially to peers, can be seen as overly critical and confrontational. The delegates soon grasped that the aim of feedback is to improve performance. Their open and engaging feedback to the faculty about how we could improve the courses in the future was refreshing and most welcome.

Prior to the visit, the faculty was concerned that cultural differences may inhibit the open faculty-delegate interactions that are key to the effectiveness of the courses in the U.K. However, the delegates were open and receptive, and useful interaction developed quickly such that the faculty believe such courses would translocate with minimal modifications.

Ultimately, any cultural and clinical differences paled into insignificance compared to the shared values, enthusiasm, and desire to improve training skills displayed by both delegates and faculty.

Knowledge and training skills improved significantly for all delegates across a range of metrics. Feedback from delegates was universally positive, albeit with suggestions of how to improve when delivering future courses.
Limitations of the study: The sample size was only 12 . This is due to the faculty: delegate directly engaged training style of the course which can accommodate only six per batch. We hope to conduct many such courses in future to increase this number, and overcome this limitation and assess the effectiveness with bigger dataset. This brief report did not involve calculation of the power of the study. This can only be addressed in future with bigger numbers.

\section{Conclusion}

The TCT course is entirely suitable to be used extensively within the Indian endoscopic community. Our plan is to deliver further courses to new delegates whilst using previous delegates as faculty observers of these courses.

Ultimately, our aim is to develop Indian faculty members so that this important course can be delivered effectively and across a wide area using faculty made up of local trainers.

\section{Conflict of Interest}

None declared.

\section{References}

1 Jørgensen OD, Kronborg O, Fenger C. A randomised study of screening for colorectal cancer using faecal occult blood testing: results after 13 years and seven biennial screening rounds. Gut 2002;50(1):29-32

2 Scholefield JH, Moss S, Sufi F, Mangham CM, Hardcastle JD. Effect of faecal occult blood screening on mortality from colorectal cancer: results from a randomised controlled trial. Gut 2002;50(6):840-844

3 Scholefield JH, Moss SM, Mangham CM, Whynes DK, Hardcastle JD. Nottingham trial of faecal occult blood testing for colorectal cancer: a 20-year follow-up. Gut 2012; 61(7):1036-1040

4 Bowles CJ, Leicester R, Romaya C, Swarbrick E, Williams CB, Epstein O. A prospective study of colonoscopy practice in the UK today: are we adequately prepared for national colorectal cancer screening tomorrow? Gut 2004;53(2):277-283

5 JETS - JAG Endoscopy Training System [online]. Available at: https://www.jets.nhs.uk/TrainingCentres.aspx. Accessed on 2 September 2020

6 JAG [online]. Available at: https://www.thejag.org.uk. Accessed 2 September 2020

7 Gavin DR, Valori RM, Anderson JT, Donnelly MT, Williams JG, Swarbrick ET. The national colonoscopy audit: a nationwide assessment of the quality and safety of colonoscopy in the UK. Gut 2013;62(2):242-249

8 Waschke KA, Anderson J, Macintosh D, Valori RM. Training the gastrointestinal endoscopy trainer. Best Pract Res Clin Gastroenterol 2016;30(3):409-419

9 Williams CB, Thomas-Gibson S. Rational colonoscopy, realistic simulation, and accelerated teaching. Gastrointest Endosc Clin N Am 2006;16(3):457-470 